\title{
Permeation and Blockage of Fine Particles Transported by Updraft through a Packed Bed
}

\author{
Hiroshi TAKAHASHI, ${ }^{1)}$ Hideki KAWAI, ${ }^{1)}$ Tokihiro KONDO2) and Masataka SUGAWARA ${ }^{3)}$ \\ 1) Muroran Institute of Technology, Department of Mechanical Systems Engineering. E-mail: hitak@plum.plala.or.jp, \\ hdkawai0@mmm.muroran-it.ac.jp 3 2) Oji Paper Co.,Ltd. 3 3) Graduate student, Muroran Institute of Technology, \\ Department of Mechanical Systems Engineering. E-mail: s1822051@mmm.muroran-it.ac.jp
}

(Received on March 24, 2011; accepted on June 6, 2011)

\begin{abstract}
The fines generated in iron making blast furnace bring about the unsteady or unstable gas/liquid permeability and solid motion. Fundamental experiment was carried out to investigate the inhomogeneous phenomena such as flow channel blockage by fine particles transferred by updraft through a fixed packed bed. The alumina sphere and coke were used for packed bed and fine particles transferred, respectively. Conclusion of this study is as follows. The principal factor controlling a criterion for the blockage is a particle diameter ratio of coke to alumina particle, and fines concentration is not a primary factor. Consideration on a hydraulic equivalent diameter of a regular packing model of spheres is effective to predict the critical diameter ratio and it resulted in good agreement with the experimentally determined. Locally blocked mass, that is, a cluster consisting of coarse alumina particles and fines through which gas is incapable of flowing is dispersed in the bed. The void fraction of packed bed being equivalent to the pressure drop, calculated from Ergun's equation, is considerably small compared with the initial value when the local blockage is in existence. Fraction of the local blockage calculated from the void fraction and static holdup of fines is $15-20 \%$ as far as the present experimental condition.
\end{abstract}

KEY WORDS: blast furnace; packed bed; gas-solid flow; solid deposition; blockage; local blockage.

\section{Introduction}

The fines deposited locally in iron making blast furnace influence seriously the gas/liquid permeability and solid motion to cause their inhomogeneous flow. ${ }^{1-3)}$ Therefore, the fundamental studies on the permeability of gas-fines two phase flow in packed bed have been carried out. It was found that the pressure drop increased suddenly when gas velocity was reduced less than a critical velocity under constant feed rate of fines. ${ }^{4,5)}$ Blockage phenomenon of fines was also confirmed. ${ }^{5)}$ The study with various combination of fine material and packed coarse material indicated also the fines behavior was affected by the surface roughness of coarse material. ${ }^{6)}$ However, the steady flow defined as fines supplying rate is equal to fines discharging rate from packed bed, was chosen as the subject of those studies. Transient accumulation behavior of coke fines was also studied, ${ }^{7)}$ but limited to such a system as steady state could be secured.

General trend of blast furnace operation in recent years directs at the low reducing agents rate and supply of a large amount of pulverized coal at tuyere. Fines generated in such an operation are believed to be considerable in amount and they would bring about unstable or unsteady behavior of blast furnace. Therefore, study on unsteady or inhomogeneous behavior caused by fines has become very important. The object of the present study is to clarify a criterion for the blockage by obstructing/plugging of flow channel due to fines transported by updraft and to confirm that, in general, the blockage may occur locally too. A packed bed with nonmoving particles is used. Coke particle for fines and alumina sphere for coarse packed bed are chosen, respectively. The result suggests that the particle diameter ratio defined by the ratio of fine to coarse particle diameter has serious effect on the blockage criterion and further, the cluster defined by a mass of local blockage consisting of coarse particles and fines through which gas permeation is not easy, might be dispersed in the bed. Estimation of the fraction of local blockage is tried also.

\section{Experimental Apparatus and Method}

The experimental apparatus is similar to the one used in the literature. ${ }^{4,5)}$ The schematic diagram is shown in Fig. 1. The column for packed bed consists of acrylic resin pipe of $100 \mathrm{~mm}$ inner diameter, $5 \mathrm{~mm}$ thickness and $530 \mathrm{~mm}$ height.

The static pressure drops in every $120 \mathrm{~mm}$ distance, $\Delta p_{1}$ to $\Delta p_{4}$ in Fig. 1, are measured by pressure transducers. The recovery and diffusion parts of $60^{\circ}$ corn angle in which glass beads of $12 \mathrm{~mm}$ diameter are packed, are installed at top and bottom of the column, respectively. It is confirmed that the glass beads does not catch the fines. The vertical column is separated from the corn parts by flanges between which a wire mesh of $2 \mathrm{~mm}$ opening size is inserted. Physical properties of packed particle and transported fine particle are listed in Table 1. The diameter of alumina sphere and fine coke is the geometrical mean of adjacent sieve aperture 


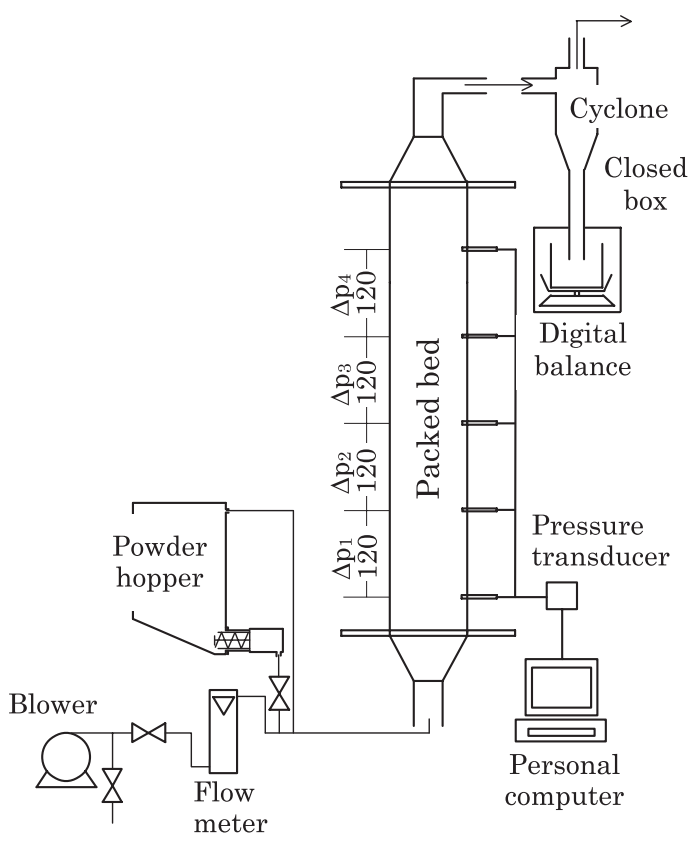

Fig. 1. Experimental apparatus.

Table 1. Physical properties of particles.

\begin{tabular}{|c|c|c|c|c|}
\hline Packed material & \multicolumn{4}{|c|}{ Alumina sphere } \\
\hline$D_{p}(\mathrm{~mm})$ & \multicolumn{2}{|c|}{2.60} & \multicolumn{2}{|c|}{$8 \quad 4.48$} \\
\hline$\rho_{\mathrm{a}}\left(\mathrm{kg} / \mathrm{m}^{3}\right)$ & \multicolumn{2}{|c|}{1500} & \multicolumn{2}{|c|}{1106} \\
\hline $\begin{array}{r}\text { Sphericity } \phi(-)^{*)} \\
\text { Transported material }\end{array}$ & \multicolumn{4}{|c|}{ Fine coke $\left.\left(\rho_{\mathrm{a}} \approx 1369 \mathrm{~kg} / \mathrm{m}^{3}\right)^{* *}\right)$} \\
\hline$D_{k}(\mathrm{~mm})$ & 0.326 & 0.388 & 0.461 & 0.596 \\
\hline$\left.u_{t}(\mathrm{~m} / \mathrm{s})^{* * *}\right)$ & 1.70 & 2.06 & 2.43 & 3.15 \\
\hline
\end{tabular}

size obtained by sieve analysis. The initial void fraction of packed bed, $\varepsilon_{0}$, is determined from the total mass of alumina spheres required to fill up the column and the apparent density. Alumina sphere is charged in such a way as to keep the total mass roughly constant in every run by tapping carefully the column wall. The obtained initial void fraction $\left(\varepsilon_{0}\right)$ is about $0.38-0.39$. Fine coke is drawn out at constant rate from powder hopper by screw feeder and transported to the bottom of packed bed by air. The powder hopper and the bottom of packed bed are kept constant in pressure connecting with each part by an air pipe. The air supply is regulated manually at constant flow rate. Fine coke discharged from top of the packed bed is collected by cyclone and the mass is continuously measured by digital balance. Static holdup of coke fines in the packed bed is determined measuring whole mass of fines trapped after run finish. The total mass of supplied fines is determined from the sum of the mass measured by digital balance and the static holdup in the bed. The supplying rate of fine coke is calculated by dividing the total mass of supplied fines by run time.

Figure 2 shows a device settled at the bottom of packed bed. Figure 2(a), say type A, has no device, i.e., the alumina spheres for test section are packed in whole volume of the vertical column. The other shown in Fig. 2(b), say type B, is that the particles for test section are located on an extra

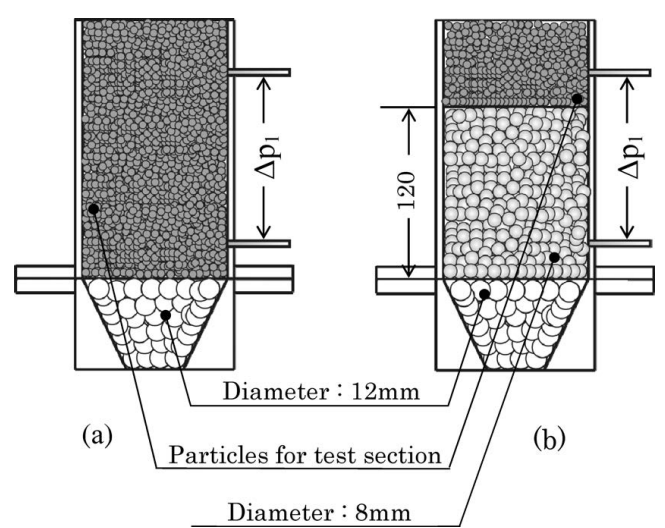

Fig. 2. Extra bed settled at the bottom of test section. (a) Type A without extra bed, (b) Type B with extra bed filled by particle of $8 \mathrm{~mm}$ diameter.

packed bed consisting of a larger alumina particle of $8 \mathrm{~mm}$ diameter. The fines can be transported without forming blockage through this extra packed bed. When a blockage takes place at the bottom of the test section, that is, just on the extra bed, a remarkable increase in pressure drop $\Delta p_{1}$ can be detected in Type B. While $\Delta p_{1}$ in type A does not show such a remarkable increase because the blockage takes place below the lower pressure tap for $\Delta p_{1}$.

Blockage by fines is judged from the change of pressure drop with time based on the following phenomena.

1) The pressure drop $\Delta p_{1}$ to $\Delta p_{4}$ reaches a limit of increase. This is caused from that air supply is restricted because the blower is beyond the capacity due to large drag force by blockage.

2) Remarkable increase of pressure drop $\Delta p_{1}$ in Type B, described before.

The blockage is also judged from recovery amount of the fine coke measured by the digital balance. That is, a recovery rate of fines is defined as follows.

Recovery rate $\eta=$ (mass collected per unit time by digital balance)/(mass supplied per unit time)

where $\eta=1$ means steady flow with no blockage and $\eta=$ 0 is for perfect blockage.

The experimental condition is as follows. Gas superficial velocity $u_{f}=0.354-1.24 \mathrm{~m} / \mathrm{s}$, where the interstitial velocity of pure gas $u_{f} / \varepsilon_{0}$ is chosen the value close to the terminal velocity $u_{t}$ of a fine particle. Mass flux of fines $G_{s}=0.062$ $0.256 \mathrm{~kg} / \mathrm{m}^{2} \mathrm{~s}$, concentration of fines in gas-fines mixture $C_{s}=0.052-0.291 \mathrm{~kg} / \mathrm{m}^{3} . C_{s}$ is calculated from the relation $C_{s}=Q_{s} /\left(Q_{v}+Q\right)$, where fines mass flow rate $Q_{s}=(\pi / 4)$ $D_{T}^{2} G_{s}$, volumetric flow rate of fines $Q_{v}=Q_{s} / \rho_{\mathrm{a}}$ and gas flow rate $Q=(\pi / 4) D_{T}^{2} u_{f}$. In this work, the relation $C_{s}=G_{s} / u_{f}$ can be approximated because the term $Q_{v}$ is negligible small compared with $Q$.

\section{Experimental Results and Discussion}

\subsection{Effect of Particle Diameter Ratio on Permeability of Fines Flow}

The particle diameter ratio defined by $\lambda=D_{k} / D_{p}$, where $D_{k}$ is diameter of fine coke and $D_{p}$ is diameter of alumina sphere, is shown in Table 2. In this section, the results 
obtained at the gas superficial velocity $u_{f} \approx 0.88 \mathrm{~m} / \mathrm{s}$ and fines mass flux $G_{s}=0.062-0.066 \mathrm{~kg} /\left(\mathrm{m}^{2} \cdot \mathrm{s}\right)\left[C_{s}=0.070-\right.$ $\left.0.075 \mathrm{~kg} / \mathrm{m}^{3}\right]$, are shown and discussed.

\subsubsection{Case of $D_{p}=3.68 \mathrm{~mm}$}

Figures 3-6 show the change of pressure drop $\Delta p_{\mathrm{i}}(\mathrm{i}=1-$ 4 ) and recovery rate $\eta$ with time. Figure 3 is for the case $\lambda=$ 0.089 . The pressure drops in each section, $\Delta p_{1}-\Delta p_{4}$, are nearly equal which means no distribution of fines holdup in axial direction and they approach a constant value with time. The recovery rate $\eta$ reaches unity about 30 minutes and the flow attains a steady state where fines deposition on to packed particles and the re-entrainment is in equilibrium. Figure 4 is for the case $\lambda=0.105$. The pressure drop in lower section of packed bed is somewhat higher than that in upper section, but each pressure drop curve has a tendency to reach a constant value with time. Increase of the pressure drop with time means that interstitial flow channel for gassolid flow becomes gradually narrow due to increasing of

Table 2. Particle diameter ratio $\lambda$.

\begin{tabular}{ccccc}
\hline Packed particle & \multicolumn{5}{c}{ Fine coke diameter $D_{k}(\mathrm{~mm})$} \\
Diameter $D_{p}(\mathrm{~mm})$ & 0.326 & 0.388 & 0.461 & 0.596 \\
\cline { 2 - 3 } & \multicolumn{4}{c}{$\lambda=D_{k} / D_{p}$} \\
\cline { 2 - 3 } 2.60 & 0.125 & 0.149 & - & - \\
\cline { 3 - 4 } 3.68 & 0.089 & 0.105 & 0.125 & 0.162 \\
4.48 & 0.073 & 0.087 & 0.103 & 0.133 \\
\hline
\end{tabular}

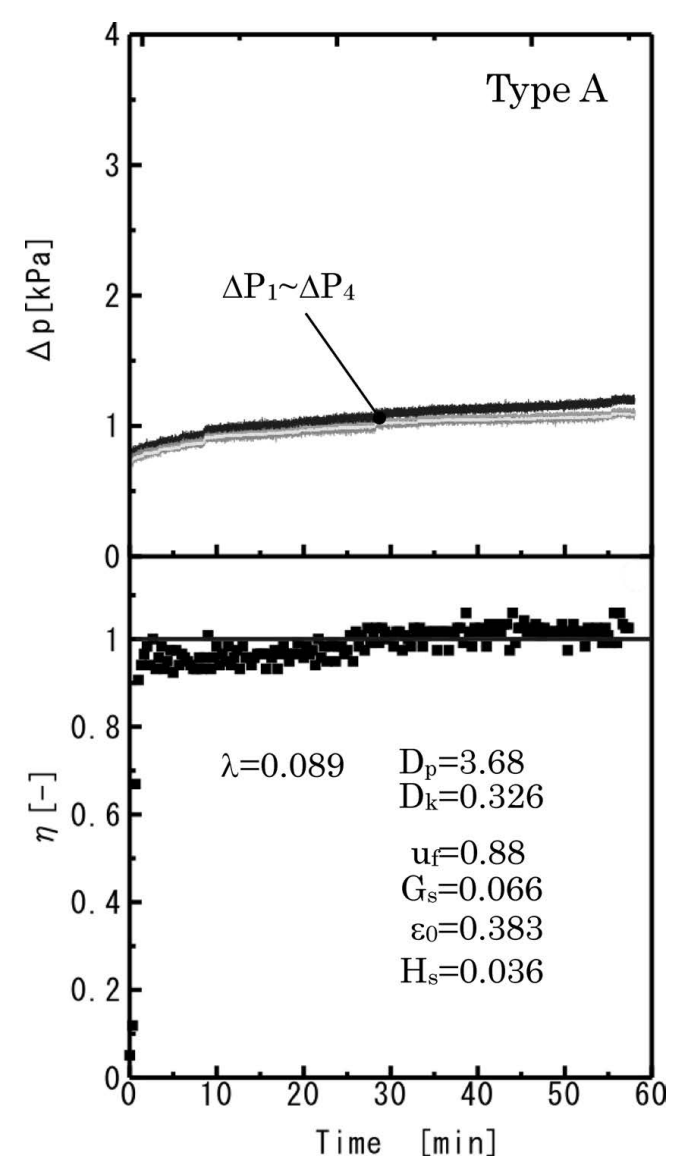

Fig. 3. Change of $\Delta p$ and $\eta$ with time, $D_{p}=3.68 \mathrm{~mm}, \lambda=0.089$ and $u_{f}=0.88 \mathrm{~m} / \mathrm{s}$.

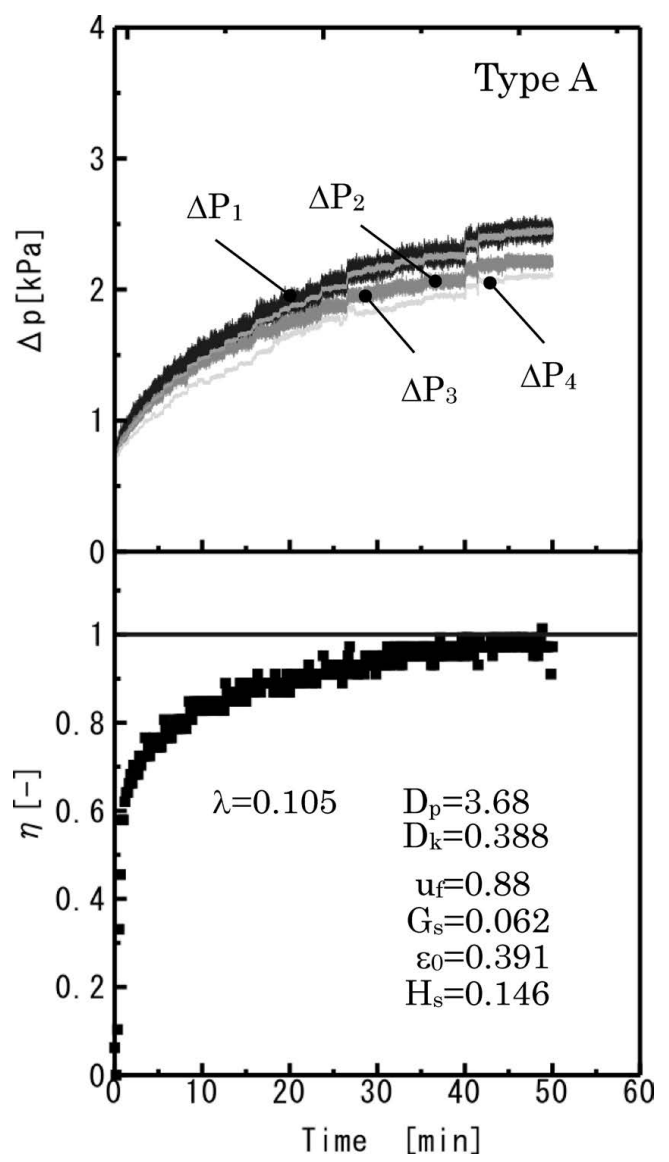

Fig. 4. Same as Fig. 3 , but $\lambda=0.105$.

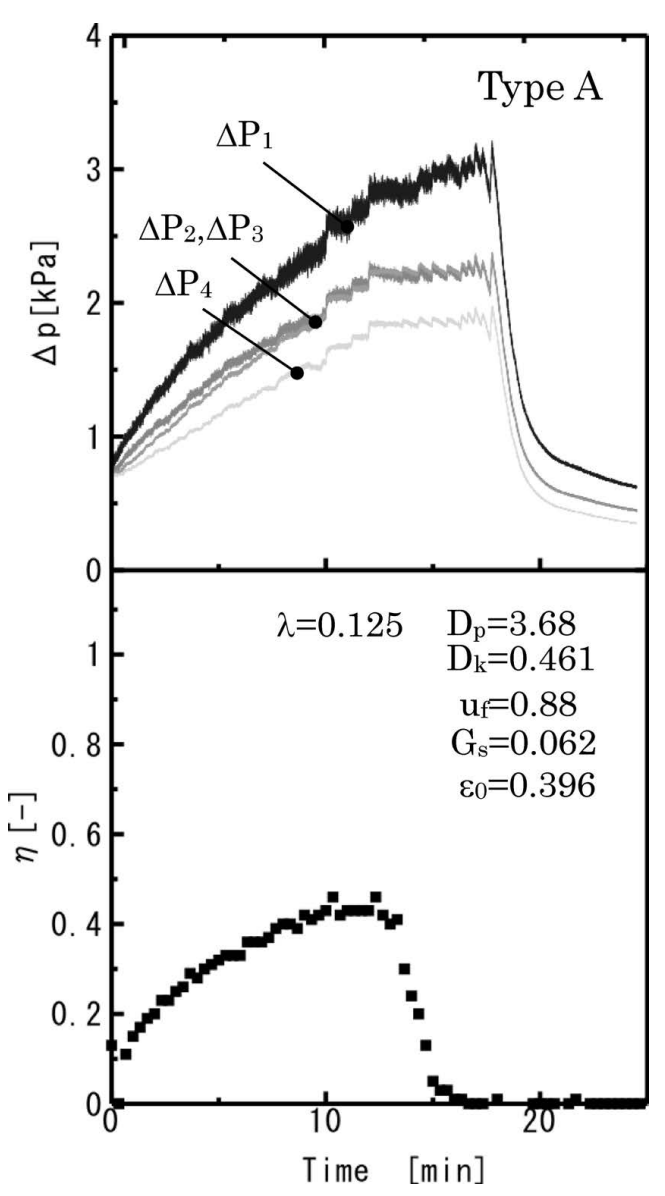

Fig. 5. Same as Fig. 3 , but $\lambda=0.125$. 
fines static holdup. Actually, the amount of static holdup $H_{S}$ increases as $0.036 \mathrm{~kg}$ at $t=58 \mathrm{~min}$. in Fig. 3 and $0.146 \mathrm{~kg}$ at $t=50 \mathrm{~min}$. in Fig. 4. However, since $\eta$ approaches unity, the accumulation of fines will decrease gradually to attain a steady flow at last. The time required for steady flow may depend on the experimental condition. For example, Hidaka et $a l .{ }^{7)}$ report an extremely short time as 5-10 min compared with Figs. 3 and 4, which may be due to a larger initial void fraction $\left(\varepsilon_{0}=0.51\right)$ and smaller diameter ratio $\lambda$ than in the present work. Figure 5 is for the case $\lambda=0.125$ with larger fine coke than in Fig. 4 . The pressure drop is distinctly large in lower section suggesting higher dynamic holdup in flow channel and this tendency is similar to the previous work. ${ }^{6)}$ In the period after $t=12-13 \mathrm{~min}$., pressure drop does not show a distinct increase, resulting from that the blower is beyond the capacity as described before, and then the sudden decrease indicates no air supply due to perfect blockage of flow channel by fines. The accumulation of fines was visually observed at a limited region just on the lower flange. The blockage starts from an earlier stage judging from the change of recovery rate and the perfect blockage attains about $t=17-18$ min corresponding to the sudden decrease of pressure drop. Figure 6 , for the case $\lambda=0.162$ larger than in Fig. 5, shows the rapid increase of pressure drop due to the packing mode Type B and following sudden drop, and indicates the perfect blockage from both the change of $\Delta p$ and $\eta$ with time.

Comparison between initial interstitial gas velocity $u_{0}=$ $u_{f} / \varepsilon_{0}$ and terminal velocity of a fine coke $u_{t}$ is as follows. Figure $3\left[u_{0}=2.3 \mathrm{~m} / \mathrm{s}, u_{0}>u_{t}\right]$, Fig. $4\left[u_{0}=2.25 \mathrm{~m} / \mathrm{s}, u_{0}>\right.$

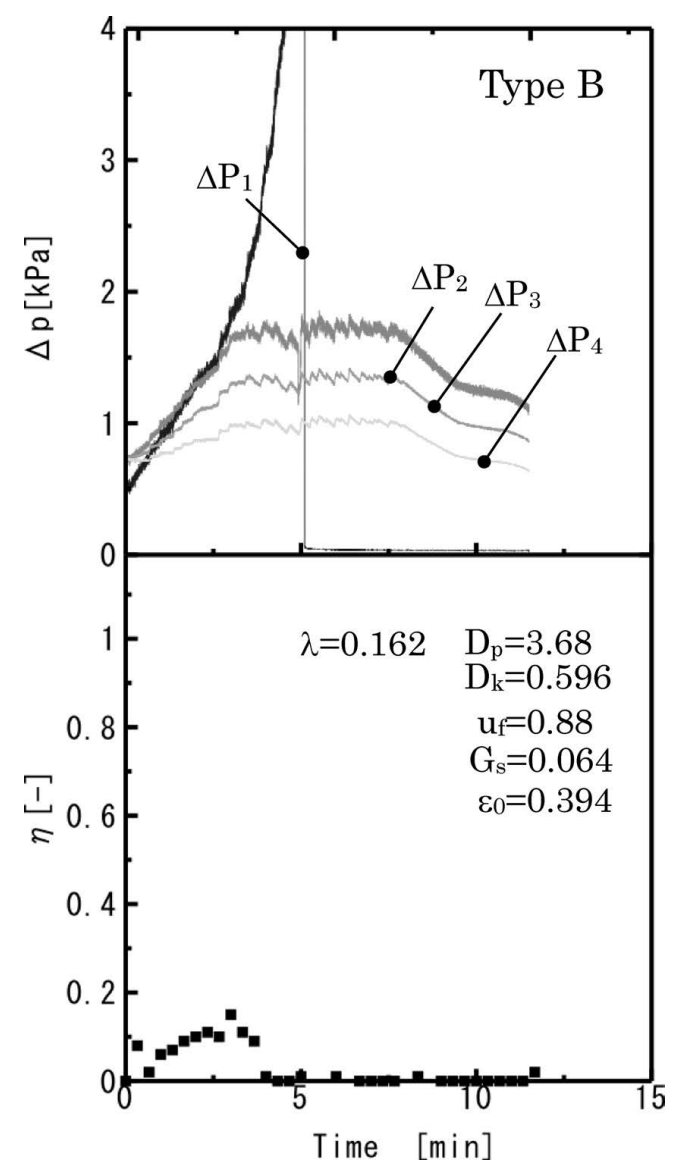

Fig. 6. Same as Fig.3, but $\lambda=0.162$. $\left.u_{t}\right]$, Fig. $5\left[u_{0}=2.22 \mathrm{~m} / \mathrm{s}, u_{0}<u_{t}\right]$ and Fig. $6\left[u_{0}=2.23 \mathrm{~m} / \mathrm{s}\right.$, $\left.u_{0}<u_{t}\right]$. So far as the above results are given, the flow may approach steady state when $u_{0}>u_{t}$ and the flow results in blockage when $u_{0}<u_{t}$. This logic will discuss successively in the following sections.

\subsubsection{Case of $D_{p}=4.48 \mathrm{~mm}$}

When particle diameter ratio $\lambda$ equals to 0.073 and 0.087 , no difference in $\Delta p_{1}$ to $\Delta p_{4}$ was recognized and a steady flow attained with $\Delta p=$ constant and $\eta=1$ in the same manner as shown in Fig. 3. The results for the cases $\lambda=0.103$ and 0.133 are shown in Figs. 7 and $\mathbf{8}$, respectively. Figure 7 shows that the pressure drops $\Delta p_{1}$ to $\Delta p_{3}$ are almost same value but increase with time, on the other hand, the recovery rate $\eta$ reaches unity at about $40 \mathrm{~min}$. Although the flow is may be still unsteady state since $\Delta p_{\mathrm{i}}$ increases with time, $\eta \approx 1$ suggests the flow is close to steady state. The behavior in $\Delta p$ and $\eta$ is similar to in Fig. 4. This experimental condition $(\lambda=0.103)$ may be in a transient range from steady flow to blockage. It is judged for such a behavior as in Figs. 7 and 4 that the steady flow would attain or the perfect blockage would not occur, even if a local blockage discussed later may be in existence. Figure 8 is the result for the case $\lambda=0.133$ and the packing mode is Type B. A low value of $\Delta p_{1}$ is due to the presence of the extra bed of larger permeability shown in Fig. 2(b), and $\Delta p_{2}$ to $\Delta p_{4}$ increase with time by the same manner as in Fig. 7. On the other hand, $\eta$ does not reach unity, which indicates the deposition

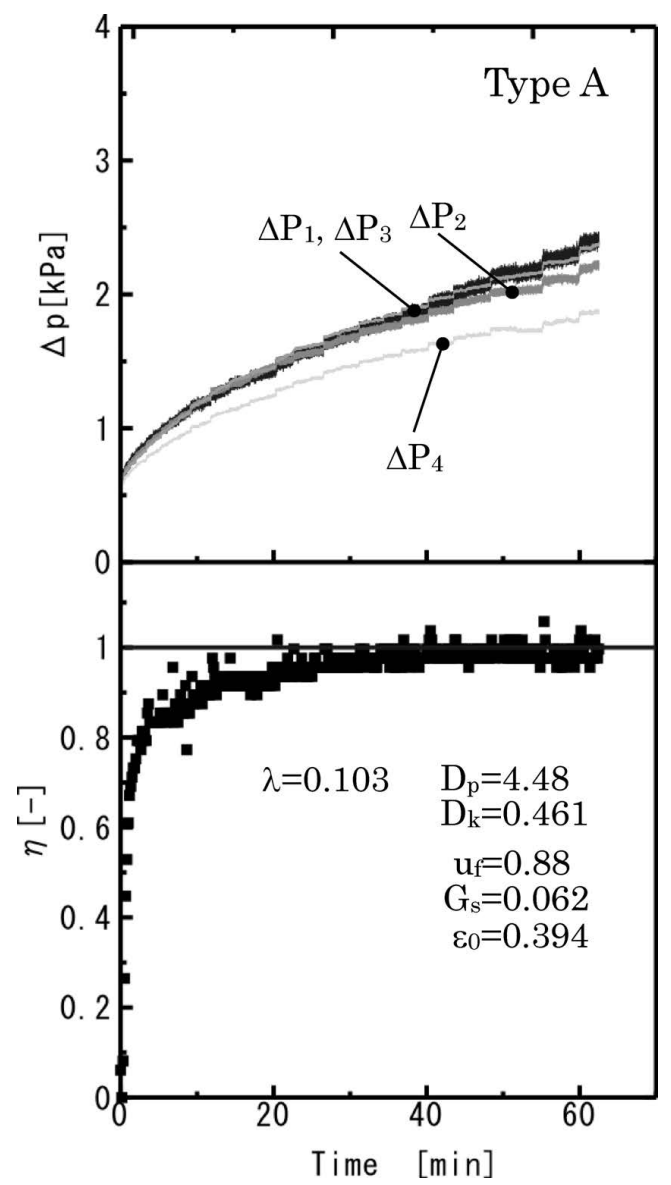

Fig. 7. Change of $\Delta p$ and $\eta$ with time, $D_{p}=4.48 \mathrm{~mm}, \lambda=0.103$ and $u_{f}=0.88 \mathrm{~m} / \mathrm{s}$. 


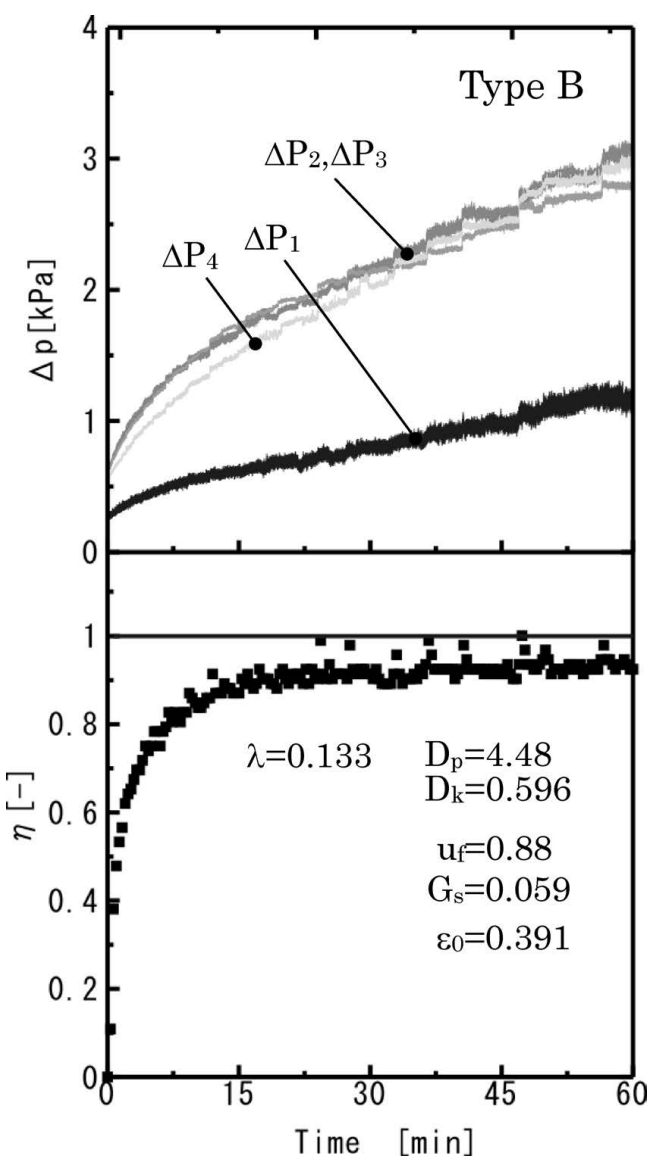

Fig. 8. Same as Fig. 7, but $\lambda=0.133$.

of fines on to packed particles still proceeds. This situation means that the blockage will take place finally. The values of $u_{0}\left(=u_{f} / \varepsilon_{0}\right)$ and $u_{t}$ are as follows. Figure $7\left[u_{0}=2.23 \mathrm{~m} / \mathrm{s}\right.$, $\left.u_{0}<u_{t}\right]$ and Fig. $8\left[u_{0}=2.25 \mathrm{~m} / \mathrm{s}, u_{0}<u_{t}\right]$.

\subsubsection{Case of $D_{p}=2.60 \mathrm{~mm}$}

The results are shown in Figs. $9(\lambda=0.125)$ and $\mathbf{1 0}(\lambda=$ $0.149)$. The blockage can be clearly recognized from the changes of $\Delta p_{\mathrm{i}}$ and $\eta$ with time. Regardless of the blockage, the relation $u_{0}>u_{t}$ hold true in both cases, i.e., $u_{0}=2.25 \mathrm{~m} / \mathrm{s}$ and $u_{t}=1.7 \mathrm{~m} / \mathrm{s}$ in Fig. 9 and $u_{0}=2.25 \mathrm{~m} / \mathrm{s}$ and $u_{t}=2.06$ $\mathrm{m} / \mathrm{s}$ in Fig. 10.

Based on the discussion relating to the particle diameter ratio $\lambda$, the transient region between blockage and flow is assumed with bold line in Table 2 . The blockage may occur in the condition that $\lambda$ is larger than $0.11-0.12$ in the present experimental condition.

It is also suggested that the criterion for blockage can not be determined from simple comparison of $u_{0}$ with $u_{t}$.

\subsection{Effect of Fines Concentration}

The experiment is carried out with two, three and four times the fines mass flux, $G_{s}=0.062$, shown in Fig. 4 , to investigate how the increase of fines concentration affects the permeation of fines. Figures $\mathbf{1 1}$ and $\mathbf{1 2}$ show the results for the cases of three and four times the mass flux, respectively. $\Delta p$ changes stepwise with time, which is caused from that the manual control to keep constant gas flow rate was difficult due to high concentration of fines. $\Delta p$ in the higher fines concentration gives the higher value. However, the

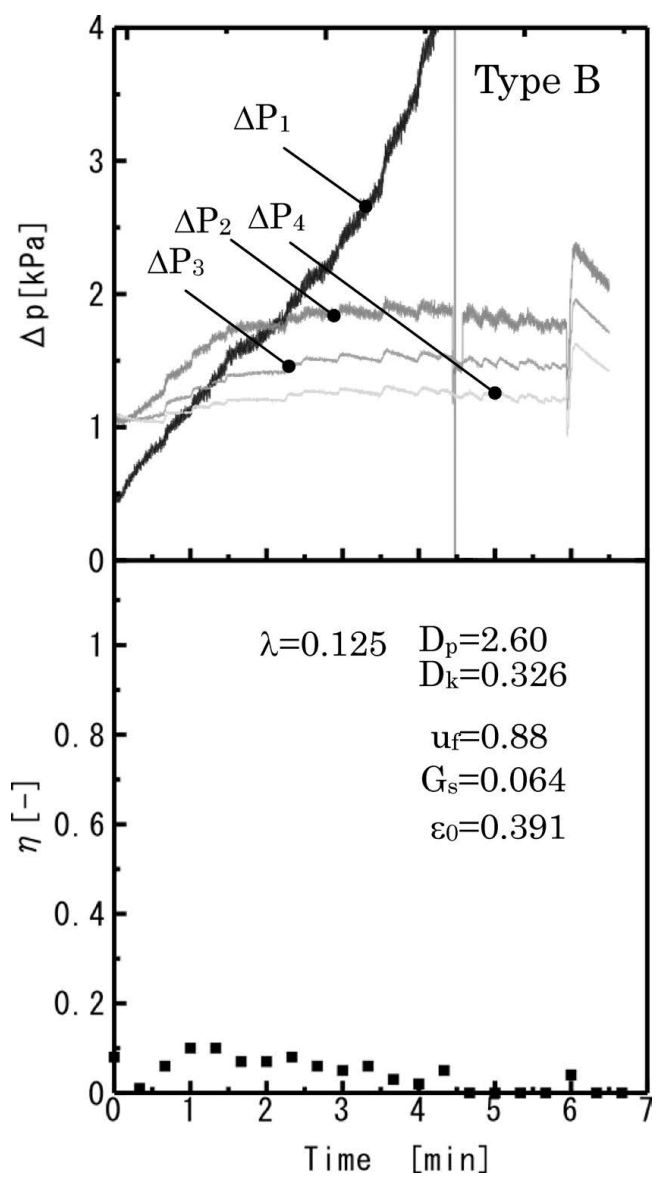

Fig. 9. Change of $\Delta p$ and $\eta$ with time, $D_{p}=2.60 \mathrm{~mm}, \lambda=0.125$ and $u_{f}=0.88 \mathrm{~m} / \mathrm{s}$.

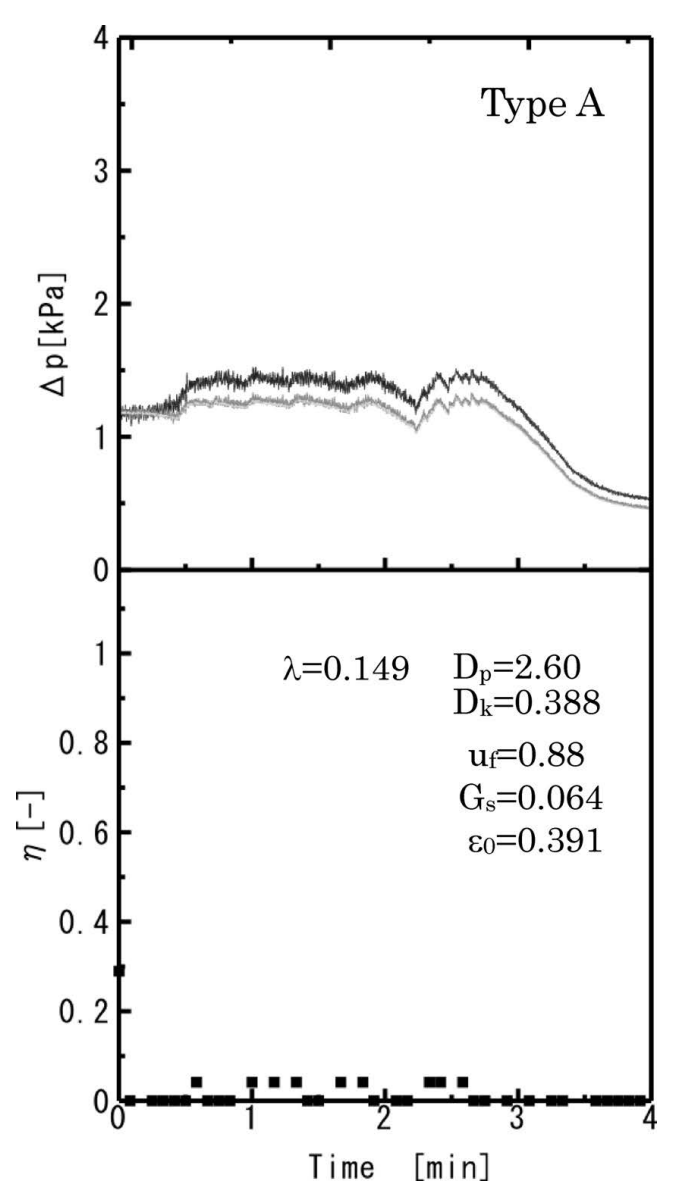

Fig. 10. Same as Fig. 9, but $\lambda=0.149$. 


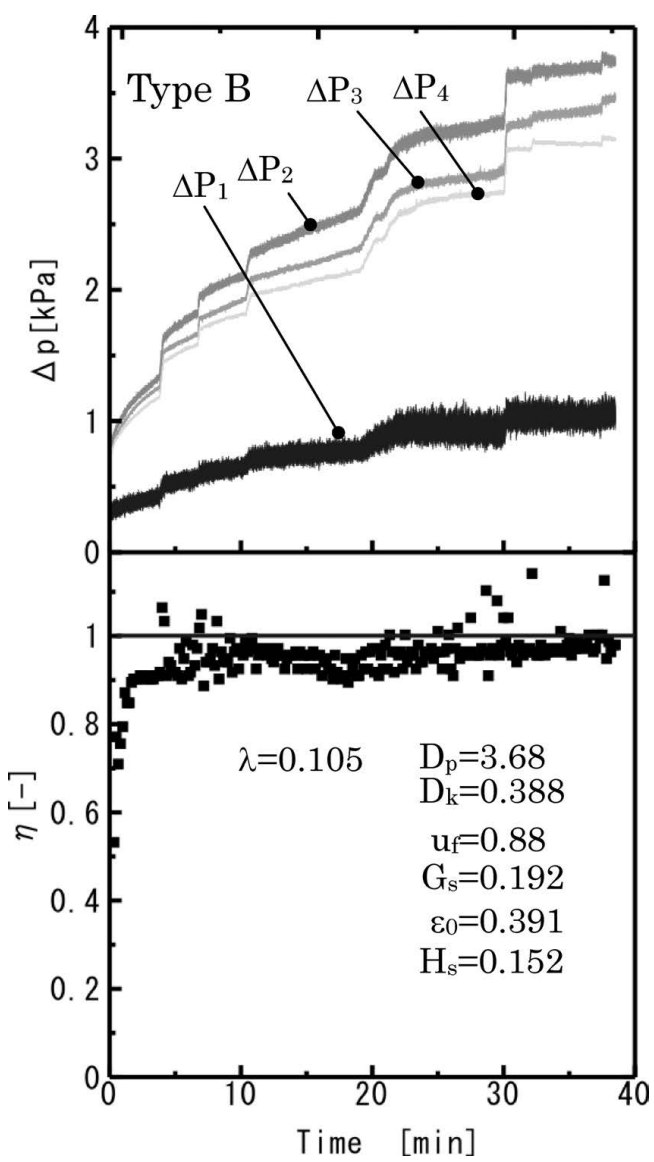

Fig. 11. Change of $\Delta p$ and $\eta$ with time, three times the fines mass flux in Fig. 4.

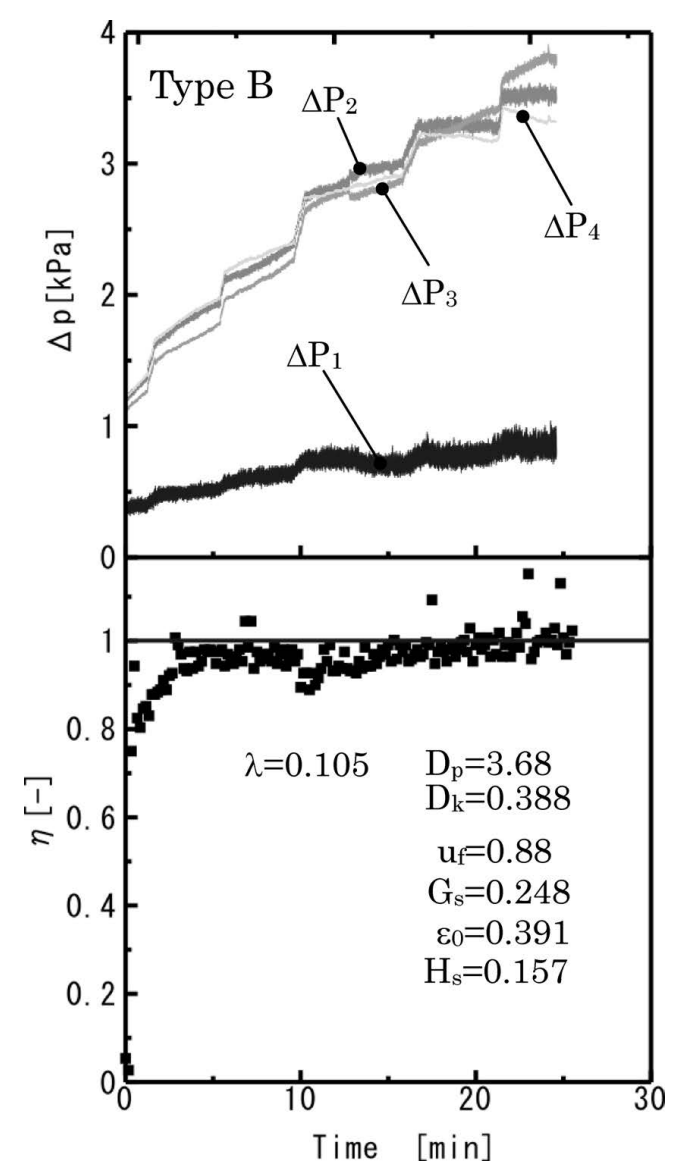

Fig. 12. Same as Fig. 11, but four times the fines mass flux in Fig. 4 . relation $\eta \approx 1$ suggests the flow is close to steady state as discussed before concerning with Figs. 4 and 7. The important thing is that the static holdup $H_{s}$ after run finish is almost the same in Figs. 4, 11 and 12 regardless the difference of run time and fines concentration. Accordingly, the fines concentration would not be a primary factor for the blockage.

\subsection{Hydraulic Equivalent Diameter and Blockage Cri- terion from a Model Packing}

Cubic regular packing as a model structure was applied to discus the entrainment and segregation of fine sintered ores and coke in a moving bed. ${ }^{8)}$ A hypothetical packing structure of spheres with equal diameter is proposed here also to evaluate hydraulic equivalent diameter of interstitial flow channel of the packed bed and to confirm for the diameter ratio $\lambda$ to play important role on the permeability of fines. As a model packing structure of the initial virgin packed bed, a composite structure consisting of 50 vol.\% cubic structure $\left(\varepsilon_{0}=0.476\right)$ and 50 vol.\% rhombic structure $\left(\varepsilon_{0}=0.302\right)$ is assumed here on the reason that the geometrical mean void fraction of the composite packing, $\varepsilon_{0}=$ 0.379 , is close to the initial void fraction, $\varepsilon_{0} \approx 0.38$, in this experiment. The structures are shown in Fig. 13. Average hydraulic equivalent diameter $\overline{D_{e}}$ of flow channel is evaluated by the relation $4 \bar{S} / \bar{Y} \cdot \bar{S}$ is mean sectional area of flow channel and $\bar{Y}$ is mean periphery length. For cubic structure (Fig. 13(a)), $\bar{Y}=3.45 D_{p}, \bar{S}=0.607 D_{p}{ }^{2}$ and hence, $\overline{D_{e}}=$ $0.704 D_{p}$ (Appendix). Similarly, for rhombic structure (Fig. 13(b)), $\bar{Y}=3.45 D_{p}, \bar{S}=0.473 D_{p}{ }^{2}$ and hence $\overline{D_{e}}=0.548 D_{p}$. Applying geometrical mean of the both, the relation $\overline{D_{e}}=$ $0.621 D_{p}$ is assumed here for the composite structure. It is known empirically that particle flow through an orifice is impossible when the orifice diameter is less than about 5 times the particle diameter. Extending this empirical rule to the flow channel with hydraulic equivalent opening $\overline{D_{e}}$, the relation $5 D_{k}=\overline{D_{e}}$ is assumed here as a critical condition for fines to be able to flow. Using the relation $\overline{D_{e}}=0.621 D_{p}$, as a result, the following critical diameter ratio is obtained for the particle bed of the model packing structure.

$$
D_{k} / D_{p}=0.12
$$

The above equation is of first approximation because it is derived under no fines deposition, on the other hand, the

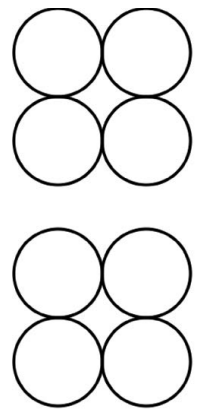

(a)
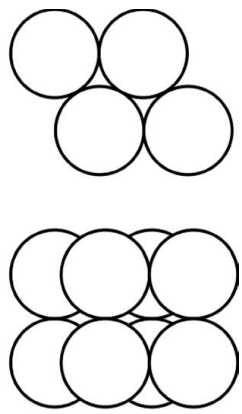

(b)
Fig. 13. Regular packing of sphere. (a) cubic packing $\left(\varepsilon_{0}=0.476\right)$ and (b) rhombic packing $\left(\varepsilon_{0}=0.302\right)$. Flow direction: perpendicular to the sheet in upper view and parallel to the sheet from bottom to top in lower view. 
advantage is to give directly the critical condition. Equation (2) agrees fairly well with the experimentally determined critical diameter ratio $\lambda=0.11-0.12$ shown in Table 2 . It is evident for the diameter ratio $D_{k} / D_{p}$ to be a principal factor for the blockage.

Sibata et al. ${ }^{5)}$ state that the blockage would take place when fines deposition increases to a limit amount and the relation $D_{e q} * / D_{k}<5.5-6$ holds true, where $D_{e q} *$ is a hydraulic equivalent diameter of packed bed with fines. However, the amount of fines deposited is required to be known for determining the operational critical point. Development of a method for predicting the fines holdup during unsteady operation is expected.

The present hydraulic equivalent diameter and hence, the critical diameter ratio depends on the initial void fraction of bed. Therefore, the critical $D_{k} / D_{p}$ for a moving bed such as blast furnace would be expected to be larger than that given in Eq. (2), because the void fraction in a moving state is, in general, larger than in the present packed state.

\subsection{The Effect of Gas Flow Rate}

The effect of gas flow rate on the permeation of fines flow is studied changing the gas superficial velocity from $u_{f}=$ $0.353 \mathrm{~m} / \mathrm{s}$ to $1.24 \mathrm{~m} / \mathrm{s}$ under the ratio $\lambda=0.105$. The conditions except for $u_{f}$ are the same as in Fig. 4 . The fines recovery rates at $u_{f}=0.353 \mathrm{~m} / \mathrm{s}$ and $u_{f}=1.24 \mathrm{~m} / \mathrm{s}$ are shown in Figs. 14 and 15, respectively. Figure 14 with low gas velocity shows the perfect blockage at about $36 \mathrm{~min}$., and the situation would correspond to the operation below a critical gas flow rate for blockage stated in previous studies. ${ }^{4,5)}$ In Fig. 15 with high gas velocity, the time required for $\eta$ to approach unity becomes shorter than in Fig. 4.

The relationship between $\Delta p / L$ and $u_{f}$, where $\Delta p$ is an average value from $\Delta p_{2}$ to $\Delta p_{4}$ at run finish time, is shown in Fig. 16 by the symbol 0 . Experimentally obtained pressure drop for pure gas without fines $(\boldsymbol{\square})$ and the calculated pressure drop for pure gas from Ergun's equation (dotted line) are also shown in Fig. 16. Ergun's equation is given by Eq. (3).

$$
\frac{\Delta p}{L}=150 \frac{(1-\varepsilon)^{2}}{\varepsilon^{3}} \frac{\mu_{f} u_{f}}{\left(\varphi D_{p}^{2}\right)}+1.75 \frac{(1-\varepsilon)}{\varepsilon^{3}} \frac{\rho_{f} u_{f}{ }^{2}}{\varphi D_{p}} \ldots .
$$

In general, fraction of fines holdup decreases with increasing of gas velocity when mass flux of fines is kept constant and hence, pressure drop curve should have a tendency to approach the value for pure gas with increasing of gas velocity. ${ }^{5,6)}$ However, the result in Fig. 16 shows, on the contrary, that $\Delta p$ increases more and more with gas velocity than the trend with pure gas. The criterion, Eq. (2), is derived on the basis of the mean void fraction of the composite packing. The actual packed bed contains locally following regions: (a) smaller void fraction than in the rhombic structure and (b) larger void fraction than in the cubic structure. Then, local blockage by fines may take place at a denser packing region. Accordingly, the great pressure drop being away from the trend with pure gas is considered to be caused by decrease of interstitial flow channel due to this local blockage. Another try is carried out with a larger coarse particle $D_{p}=4.48 \mathrm{~mm}$ and especially prepared smaller fine particle $D_{k}=0.23$, i.e., $\lambda=0.051$. This is the case the

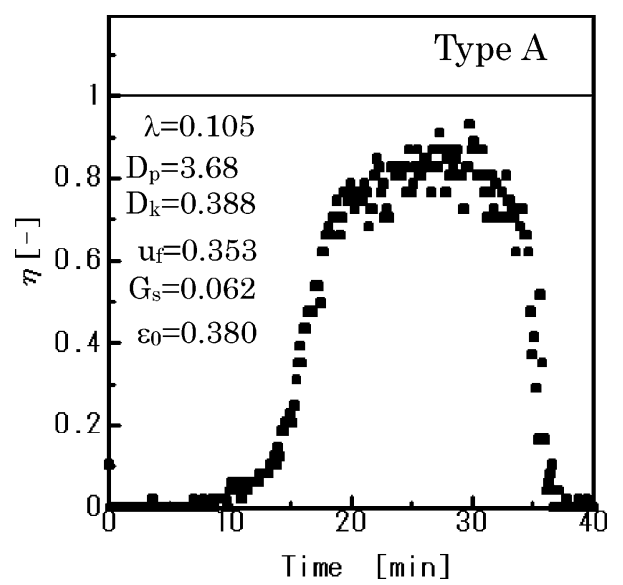

Fig. 14. Change of $\eta$ with time, $D_{p}=3.68 \mathrm{~mm}, \lambda=0.105$ and $u_{f}=$ $0.353 \mathrm{~m} / \mathrm{s}$.

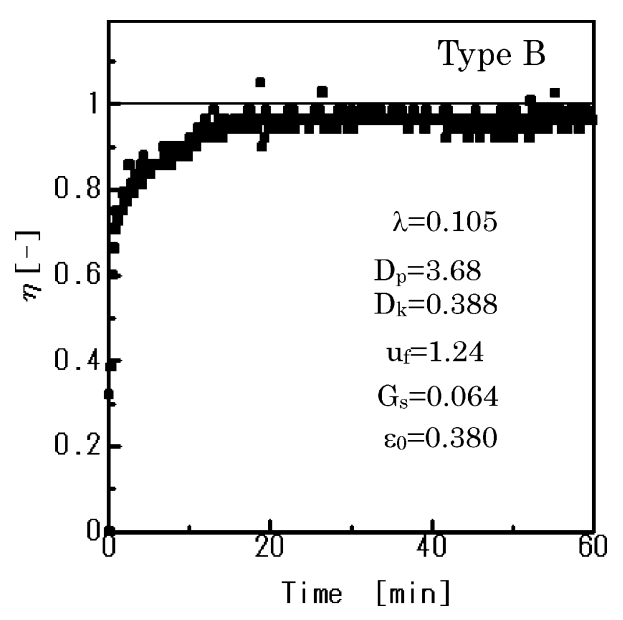

Fig. 15. Same as Fig. 14, but $u_{f}=1.24 \mathrm{~m} / \mathrm{s}$.

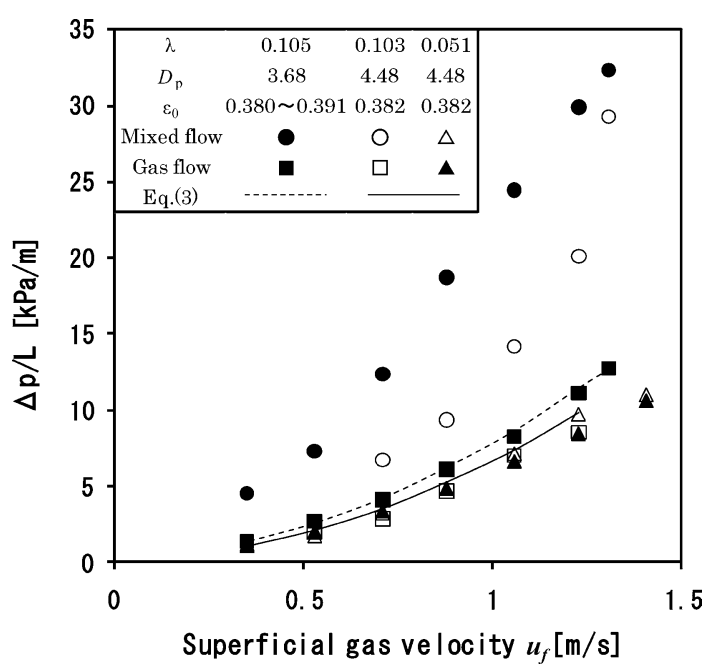

Fig. 16. Effect of $\lambda$ on the change of $\Delta p / L$ with $u_{f}$.

fines may be possible to pass through the void very easily. The result is shown in Fig. 16 with the symbol $\triangle$, showing the pressure drop curve is almost the same as that of pure gas. This result indicates that no change arises in the flow channel in both the two phase flow and pure gas flow and hence, no local blockage is caused. Further, a larger fine coke diameter $D_{k}=0.461 \mathrm{~mm}$ with the same coarse particle 
Table 3. Change of system variables with $u_{f}$ for the case $D_{p}=3.68$ $\mathrm{mm}, \lambda=0.105$ and $G_{s}=0.064 \mathrm{~kg} /\left(\mathrm{m}^{2} \cdot \mathrm{s}\right)$.

\begin{tabular}{lccccccc}
\hline $\begin{array}{c}u_{f} \\
(\mathrm{~m} / \mathrm{s})\end{array}$ & $\begin{array}{c}\varepsilon_{0} \\
(-)\end{array}$ & $\begin{array}{c}\Delta_{p} / L \\
(\mathrm{kPa} / \mathrm{m})\end{array}$ & $\begin{array}{c}H_{s} \\
(\mathrm{~kg})\end{array}$ & $\begin{array}{c}\mathcal{E}_{s} \\
(-)\end{array}$ & $\begin{array}{c}\mathcal{E}_{v} \\
(-)\end{array}$ & $\begin{array}{c}\varepsilon \\
(-)\end{array}$ & $\begin{array}{c}\alpha \\
(-)\end{array}$ \\
\hline 0.531 & 0.380 & 7.30 & 0.167 & 0.0379 & 0.342 & 0.293 & 0.141 \\
0.707 & 0.380 & 12.25 & 0.105 & 0.0238 & 0.356 & 0.290 & 0.186 \\
0.884 & 0.391 & 18.74 & 0.146 & 0.0256 & 0.365 & 0.288 & 0.212 \\
1.06 & 0.398 & 24.45 & 0.115 & 0.0261 & 0.372 & 0.293 & 0.212 \\
1.24 & 0.380 & 29.92 & 0.098 & 0.0222 & 0.358 & 0.299 & 0.164 \\
\hline
\end{tabular}

Table 4. Change of system variables with $u_{f}$ for the case $D_{p}=4.48$ $\mathrm{mm}, \lambda=0.103$ and $G_{s}=0.064 \mathrm{~kg} /\left(\mathrm{m}^{2} \cdot \mathrm{s}\right)$.

\begin{tabular}{cccccccc}
\hline $\begin{array}{c}u_{f} \\
(\mathrm{~m} / \mathrm{s})\end{array}$ & $\begin{array}{c}\varepsilon_{0} \\
(-)\end{array}$ & $\begin{array}{c}\Delta_{p} / L \\
(\mathrm{kPa} / \mathrm{m})\end{array}$ & $\begin{array}{c}H_{s} \\
(\mathrm{~kg})\end{array}$ & $\begin{array}{c}\varepsilon_{s} \\
(-)\end{array}$ & $\begin{array}{c}\varepsilon_{v} \\
(-)\end{array}$ & $\begin{array}{c}\varepsilon \\
(-)\end{array}$ & $\begin{array}{c}\alpha \\
(-)\end{array}$ \\
\hline 0.531 & 0.389 & 6.73 & 0.212 & 0.0481 & 0.341 & 0.278 & 0.185 \\
0.707 & 0.382 & 9.35 & 0.148 & 0.0336 & 0.348 & 0.292 & 0.162 \\
0.884 & 0.382 & 14.18 & 0.108 & 0.0245 & 0.358 & 0.291 & 0.186 \\
1.06 & 0.382 & 20.15 & 0.107 & 0.0243 & 0.358 & 0.285 & 0.203 \\
1.24 & 0.382 & 29.28 & 0.108 & 0.0245 & 0.358 & 0.281 & 0.214 \\
\hline
\end{tabular}

diameter $D_{p}=4.48 \mathrm{~mm}(\lambda=0.103)$ is examined. The results are shown by the symbols $\bigcirc$ and $\square$ in Fig. 16. A similar result to the case in $\lambda=0.105$ and $D_{p}=3.68 \mathrm{~mm}$ is obtained, which means the existence of local blockage. As a result of it, the relation of $\Delta p$ with gas velocity depends strongly on the existence of the local blockage.

\subsection{Fraction of Local Blockage}

The void fraction $\varepsilon$ at the run finish (1 hour after start of experiment), calculated from Eq. (3) for various gas velocity, is shown in Tables 3 and $\mathbf{4}$ for $\lambda=0.105$ and 0.103 , respectively. The initial virgin particle diameter $D_{p}$ is applied to the calculation and $\varphi=0.95$ is used (Table 1). The calculated value of $\varepsilon$ is considerably small compared with $\varepsilon_{0}$, suggesting large amount of fines holdup. Further, $\varepsilon$ is almost constant regardless of gas velocity. This may indicate the fraction of local blockage does not so much depend on gas velocity.

Figure 17 is a conceptual figure describing the distribution of fines deposited on packed particles. Fig. 17(a) is a case of homogeneous deposition of fines with no local blockage. The fraction $\varepsilon_{v}$ of the void through which the permeation of fines flow is possible, is given by

$$
\mathcal{E}_{v}=\varepsilon_{0} \text { (initial void fraction) }-\varepsilon_{s} \text { (static holdup fraction) }
$$

where $\varepsilon_{s}$ can be calculated from the amount of holdup $H_{S}$ and apparent density of coke $\rho_{\mathrm{a}}$. On the other hand, Fig. 17(b) shows a distribution of the cluster consisting of packed particles and fine cokes. The local blockage is defined here by the situation that gas flow is impossible to flow through the mass of cluster. Hence, the fraction of local blockage can be defined as follows.

Fraction of local blockage $\alpha=1-$ (fraction of void for fluid permeation)

$$
=1-\left(\varepsilon \text { from Eq. (3)) } / \mathcal{E}_{v} \ldots(5)\right.
$$

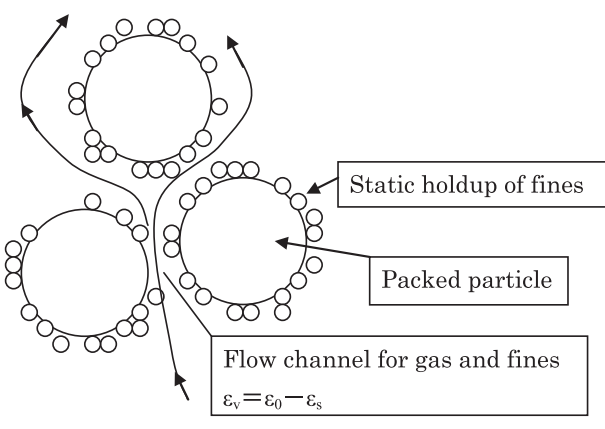

(a)

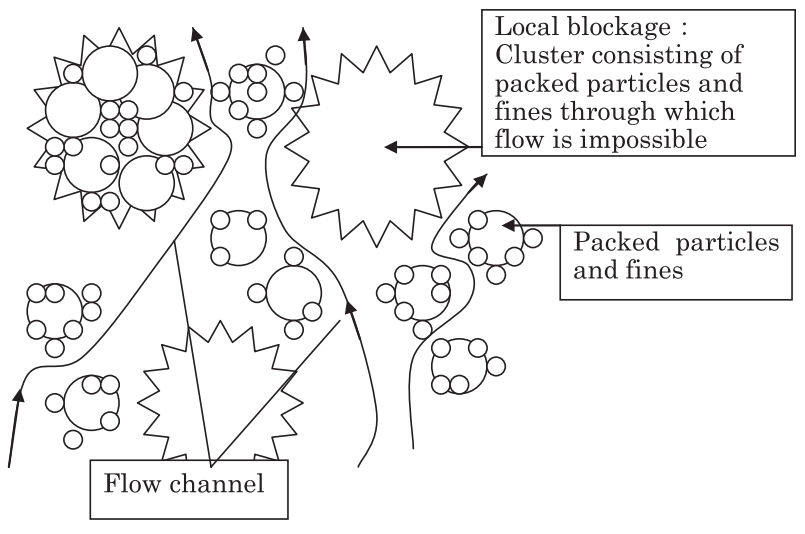

(b)

Fig. 17. Conceptual diagram illustrating fines deposition state. (a) Homogeneous deposition. (b) Local blockage by clusters consisting of deposited fines and packed bed particles.

When no local blockage, $\alpha$ is equal to 0 , then, the relation $\varepsilon=\varepsilon_{v}=$ Eq. (4) describing the situation in Fig. 17(a) holds true. The values of $\mathcal{E}_{s}, \mathcal{E}_{v}$ and $\alpha$ are listed in Tables 3 and 4, in which the relation $\varepsilon<\varepsilon_{v}$ is shown, and hence, $\alpha>0$ from Eq. (5). The fraction of local blockage estimated is nearly $0.15-0.2(15-20 \%)$ at the run finish time. The fractions of local blockage for Figs. 4, 7 and 15 are 0.212, 0.186 and 0.164 from the Tables, respectively. This means gas-solid flow proceeds accompanying with local blockage by fines.

\section{Conclusion}

The experiment was carried out, using a non-moving packed bed, in order to study the inhomogeneous or dispersed phenomena such as blockage/local blockage of packed bed by the fine particles transported by updraft. The alumina spheres were used for packing particles of the bed and coke was for fine particles transported. The following results are obtained. (1) An principal factor controlling the blockage is a particle diameter ratio $\lambda$, defined by the particle diameter of fine divided by that of packing particle. $\lambda=0.11-0.12$ is suggested as a critical value for the present packed bed. (2) The fines concentration is not a primary factor for the blockage. (3) A hydraulic equivalent diameter is evaluated based on a model packing structure consisting of a couple of regular packing, i.e., cubic and rhombic packing, in order to predict the critical particle diameter ratio. The predicted value is in fairly good agreement with the experimental result. (4) Local blockage by fines can occur 
in general. The fraction of local blockage is evaluated for the two cases, on the basis of Ergun's equation for pressure drop and measured static holdup of fines, as a result of it, the fraction is about $15-20 \%$ in percentage.

\section{Nomenclature}

$C_{S}$ : Concentration of fines $\left(\mathrm{kg} / \mathrm{m}^{3}\right)$

$\overline{D_{e}}$ : Average hydraulic equivalent diameter of flow channel in model packing $(\mathrm{m})$, calculated by $4 \bar{S} / \bar{Y}(\mathrm{~m})$

$D_{e q}{ }^{*}$ : Hydraulic diameter of packed bed including fines $(\mathrm{m})$, in the literature (5)

$D_{k}$ : Diameter of fine particle $(\mathrm{m})$

$D_{p}$ : Diameter of packed particle $(\mathrm{m})$

$D_{T}$ : Diameter of packed column (m)

$G_{s}$ : Mass flux of fines $\left(\mathrm{kg} /\left(\mathrm{m}^{2} \cdot \mathrm{s}\right)\right)$

$H_{s}$ : Total static holdup of fines in packed bed $(\mathrm{kg})$

$L$ : Interval between each pressure measuring tap (m)

$\Delta p:$ Pressure drop $(\mathrm{Pa})$

$Q:$ Flow rate of gas $\left(\mathrm{m}^{3} / \mathrm{s}\right)$

$Q_{s}:$ Mass flow rate of fines $(\mathrm{kg} / \mathrm{s})$

$Q_{v}$ : Volumetric flow rate of fines $\left(\mathrm{m}^{3} / \mathrm{s}\right)$

$\bar{S}$ : Mean sectional area of flow channel in model packing $\left(\mathrm{m}^{2}\right)$

$\bar{Y}$ : Mean periphery length of flow channel in model packing (m)

$u_{0}$ : Defined by $u_{f} / \varepsilon_{0}(\mathrm{~m} / \mathrm{s})$

$u_{f}$ : Superficial gas velocity $(\mathrm{m} / \mathrm{s})$

$u_{t}$ : Terminal velocity of a coke particle $(\mathrm{m} / \mathrm{s})$

$\alpha$ : Fraction of local blockage, defined by Eq. (5) (-)

$\varepsilon$ : Void fraction estimated from Eq. (3) (-)

$\varepsilon_{0}$ : Initial void fraction of packed bed $(-)$

$\varepsilon_{s}$ : Volumetric fraction of fines static holdup (-)

$\varepsilon_{v}$ : Fraction of the void through which gas and fines are possible to flow, defined by Eq. (4) (-)

$\eta$ : Recovery rate of fines at top of the bed, defined by Eq. (1) (-)

$\lambda$ : Diameter ratio, defined by $D_{k} / D_{p}(-)$

$\mu_{f}:$ Viscosity of gas $(\mathrm{Pa} \cdot \mathrm{s})$

$\rho_{\mathrm{a}}$ : Apparent density of coke particle $\left(\mathrm{kg} / \mathrm{m}^{3}\right)$

$\rho_{f}:$ Density of gas $\left(\mathrm{kg} / \mathrm{m}^{3}\right)$

$\varphi$ : Sphericity of packed particle (-)

\section{REFERENCES}

1) K. Kojima, T. Nishi, T. Yamaguchi, H. Nakama and S. Ida: Tetsu-toHagané, 62 (1976), 570.
2) M. Tate, Y. Kuwano, K. Suzuki, T. Chan, H. Go and M. Matsuzaki: Tetsu-to-Hagané, 62 (1976), 495.

3) H. Takahashi, H. Kawai, M. Kobayashi and T. Fukui: ISIJ Int., 45 (2005), 1386.

4) H. Yamaoka: Tetsu-to-Hagané, 72 (1986), 403.

5) K. Sibata, M. Shimizu, S. Inaba, R. Takahashi and J. Yagi: Tetsu-toHagané, 77 (1991), 236.

6) N. Hidaka, T. Matsumoto, K. Kusakabe and S. Morooka: J. Chem. Eng. Jpn., 32 (1999), 197.

7) N. Hidaka, T. Matsumoto, K. Kusakabe and S. Morooka: J. Chem. Eng. Jpn., 33 (2000), 152.

8) H. Kawai, H. Takahashi and M. Ichida: ISIJ Int., 45 (2005), 1112.

\section{Appendix}

Figure A1 represents the top and side views of cubic regular packing where length $\ell$ is a cosine of sphere radius $D_{p} / 2$ at elevation angle $\theta$ as defined in Fig. A1. The periphery length of flow channel in cubic packing, $Y(\theta)$ at $\theta=\theta$, is given as

$$
Y(\theta)=4\left(D_{p}-2 \ell\right)+2 \pi \ell, \quad \ell=\left(D_{p} / 2\right) \cos \theta
$$

The average of $Y(\theta)$ is evaluated by the form

$$
\bar{Y}=\int_{0}^{\pi / 2} Y(\theta) d \theta / \int_{0}^{\pi / 2} d \theta=3.45 D_{p}
$$

Similarly, the sectional area of flow channel $S(\theta)$ is

$$
\begin{array}{r}
S(\theta)=D_{p}{ }^{2}-(\pi / 4)(2 \ell)^{2} \ldots \ldots \ldots \\
\bar{S}=\int_{0}^{\pi / 2} S(\theta) d \theta / \int_{0}^{\pi / 2} d \theta=0.607 D_{p}{ }^{2}
\end{array}
$$

Accordingly, $\overline{D_{e}}=4 \bar{S} / \bar{Y}=0.704 D_{p}$

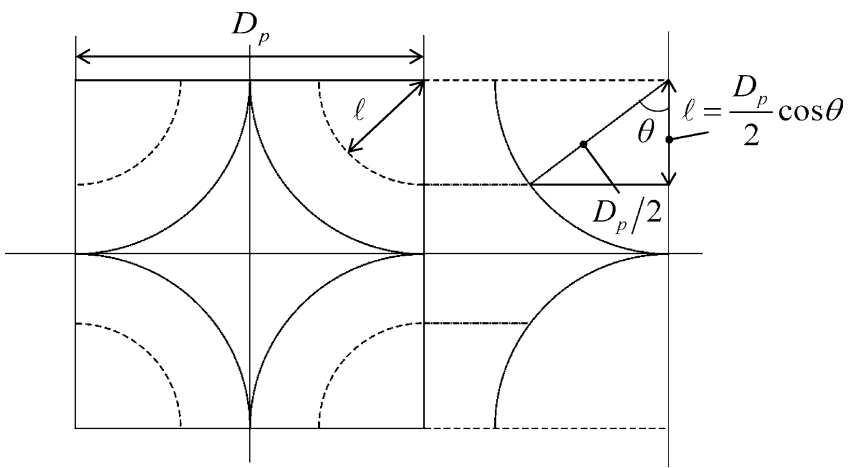

Top view

Side view

Fig. A1. Projected figure of cubic regular packing 